\title{
Biochemical differences between nano- and normal formulation of tamoxifen and other natural bioactive materials ameliorate breast cancer in experimental rats
}

\author{
Afaf Ezzat ${ }^{1}$, Abdou Osman Abdelhamid², Mostafa K. El Awady ${ }^{3}$, Reham M. Dawood ${ }^{3}$ and \\ Dina Mostafa Mohammed ${ }^{1 *}$
}

\begin{abstract}
Background: Human breast cancer is the most prevalent malignancy in women all-over the world. The aim is to look further into the effectiveness of the nanoformulation of tamoxifen and even certain bioactive compounds (yeast, isoflavone, and silymarin) and their impacts on diminishing the breast cancer progression. A single medication dosage of 7,12-dimethylbenz[a]anthracene (DMBA) was administered intragastrically by fifty-four female Sprague-Dawley rats. After fourteen days of DMBA admission, the procedure protocol actually started out. At long last, all of the experimental findings assessed, tabulated, and statistically analyzed.
\end{abstract}

Results: In contrast to the normal groups, a substantial elevation in apoptosis and lipid peroxide was observed in all nanogroups.

Conclusion: The best biochemical outcome and beneficial factors which elevate the occurrence and activation of the apoptosis process have been demonstrated by nanotamoxifen.

Keywords: Apoptosis, Bioactive components, Breast cancer, Nanoparticles, Rats, Tamoxifen

\section{Background}

Human breast cancer is an uncontrolled growth of the cells of the breast that originate from breast tissue, mostly from the inner lining of the milk ducts or the lobules as a result of mutations in the genes responsible for coordinating and maintain healthy cell growth (Angeline Kirubha et al. 2012; DeSantis et al. 2011). One of the only organs not completely developed during childbirth is the mammary gland. In puberty, pregnancy, and lactation, it undergoes intense evaluative and functional modifications. In certain cases, a single breast tumor can

\footnotetext{
*Correspondence: dina_ganna@yahoo.com

${ }^{1}$ Department of Nutrition and Food Science, National Research Centre, Dokki, Cairo 12622, Egypt

Full list of author information is available at the end of the article
}

be a combination of invasive and in situ cancer forms or mixture (Girish et al. 2014; Simpson et al. 2010). Risk factors for creating of human breast cancer can be classified into two groups: modifiable risk factors (things that can change the use of drinks, for example) and fixed risk factors (things that have never shown signs of change, for instance, age and sex) (Hayes et al. 2013). Menopause hormone replacement therapy, ionizing radiation, early age from first month to month, more experienced age period, and hereditary factor (Zhang et al. 2015; Brody et al. 2007).

The tamoxifen as selective estrogen receptor modulator is utilized in the amelioration of the early and advanced human breast cancer and to prevent human breast cancer in high-risk subjects in selected cases (Teunissen et al. 2010). 
Cancer nanotechnology with extensive application is an up and coming area. Via early detection, hope, anticipation, customized treatment, and prescription, it offers a specific approach and exhaustive innovation tower cancer. The priority research areas on which nanotechnology will have an indispensable influence are targetspecific drug therapy and early detection techniques for pathologies (Misra et al. 2010). Cancer nanotherapeutics is advancing at an enduring dimension; since the mid2000s, research and progression in the field have undergone exponential growth (Bertrand et al. 2014).

Nanotechnology applications can aid in nutrition research to obtain accurate spatial level information on the location of a nutrient or bioactive food component in a tissue, cell, or cellular component.

Human breast cancer normally ameliorates within a few weeks of the diagnosis. The type of amelioration recommended depends on the stage of the cancer, the size, the patient's age and the location of a tumor in the breast, the results of laboratory tests conducted on the cancer cells, and the stage or extent of the disease. Depending on their needs, a patient may have either one form of amelioration or a combination (Girish et al. 2014).

This research seeks new formulations that have a different impact and minimize the progression and prevalence of breast cancer through the conversion of tamoxifen and some bioactive compounds including such yeast, isoflavone, and silymarin to nanoparticles,.

The role of these drug and bioactive components in the form of nanoparticles in the progression of human breast cancer and their potential to stimulate apoptosis in human breast cancer cells and the inhibitory effect of nanoparticles on the progression of the induction of toxic material for human breast cancer in experimental animals has not been documented to date.

\section{Methods}

\section{Nanomaterials preparation}

In the Nutrition and Food Science Department at National Research Centre, all the nanomaterials used in the experiment were prepared which included silymarin and isoflavone as bioactive components, nutrients as yeast, drugs as tamoxifen (Ezzat et al. 2018, 2017, 2013). Nanonutrients, drug, and bioactive compounds were assessed by transmission electron microscopy, mass spectroscopy, and ZetaSizer Nano-ZS.

\section{Experimental animals}

Fifty-four female Sprague-Dawley rats, weighing between 60 and $80 \mathrm{~g}$, obtained from the Animal House of the National Research Centre, Egypt, were held for one week prior to the acclimatization experiment on a regular laboratory diet and water to ensure normal growth and behavior. In a temperature controlled $(23 \pm 10 \mathrm{C}), 40-60 \%$ relative humidity and artificially lit ( $12 \mathrm{~h}$ dark/light cycle) rooms free from any cause of chemical contamination, the animals were distributed and housed in individual solid bottom cages. Both animals received human treatment and were used in a compliance with Animal Experiments Guidelines. As defined by Samy et al. (2006), rats were offered a single dose $(25 \mathrm{mg} / \mathrm{kg}$ body weight $)$ of 7,12-dimethylbenz[a] anthracene (DMBA) administered intragastrically via gavage to induced breast cancer. The timeframe after DMBA administration during which the animals recovered from the toxicity caused by DMBA was two weeks, the animals were categorized into 9 groups, each with six animals, with one group of injected animals feeding as control on the basal synthetic diet. Injected animals were fed nanoparticles (yeast, tamoxifen, isoflavone, and silymarin) combined with a basal synthetic diet in four groups. Another four groups of injected animals were fed the same synthetic basal diet supplemented with normal particles (yeast, tamoxifen, isoflavone, and silymarin) as illustrated in Table 1. We researched the various effects on body weight, body gain, total food intake and food efficiency of yeast, tamoxifen, isoflavone, and silymarin. The salt and vitamin mixture formation can be determined using conventional approaches by Briggs and William (1963) and Morcos (1976).

The basal synthetic diet (Table 1) was prepared according to Ezzat et al. $(2018,2017,2013)$.

Table 1 The diet composition for different groups

\begin{tabular}{|c|c|c|c|c|}
\hline \multirow[t]{2}{*}{ Ingredients (g) } & \multicolumn{4}{|l|}{ Groups } \\
\hline & Group 1 & Group 2 & Group 3 & $\begin{array}{l}\text { Group } \\
4\end{array}$ \\
\hline Casein & 15 & 15 & 15 & 15 \\
\hline Saturated/unsaturated fat & 10 & 10 & 10 & 10 \\
\hline Sucrose & 22 & 22 & 22 & 22 \\
\hline Maize starch & 37.333 & 43.7 & 43.5 & 43.5 \\
\hline Cellulose & 4 & 4 & 4 & 4 \\
\hline Salt mixture & 4 & 4 & 4 & 4 \\
\hline Vitamin mixture & 1 & 1 & 1 & 1 \\
\hline \multicolumn{5}{|l|}{ Drugs } \\
\hline Tamoxifen & - & 0.3 & - & - \\
\hline \multicolumn{5}{|l|}{ Bioactive components } \\
\hline Isoflavone & - & - & 0.5 & - \\
\hline Silymarin & - & - & - & 0.5 \\
\hline \multicolumn{5}{|l|}{ Nutrient } \\
\hline Yeast & 6.667 & - & - & - \\
\hline Total & 100 & 100 & 100 & 100 \\
\hline
\end{tabular}




\section{Plasma and serum biochemistry}

The animals were kept fasting for $12 \mathrm{~h}$ at the end of the experimental phase that took six months for all groups, during which diethylether was added inside a desiccator to anesthesize the animals. They were then killed and the retro-orbital venous plexus extracted the blood samples. A blood sample of each animal obtained by centrifugation separating serum and plasma (Sigma labour zentrifuge GMBH, West Germany, model 2-15 3360 osterode / Hertz) for $15 \mathrm{~min}$ at $3000 \mathrm{rpm}$ and processed in $-20{ }^{\circ} \mathrm{C}$ for biochemical parameters calculation.

\section{Biochemical parameters under investigation}

(a) Enzyme-linked immunosorbent assay (ELISA) for rat apoptosis-inducing factor (AIF) quantitative determination: Apoptosis ELISA kit was purchased from Glory Science Co., Ltd (USA).

(b) Rat 8-hydroxy-deoxyguanosine (8-OHdG) detection enzyme-linked immunosorbent assay (ELISA): (8-OHdG) ELISA kit was purchased from Glory Science Co., Ltd (USA).

(c) Enzyme-linked immunosorbent assay (ELISA) for ErbB-2 (ERBB2) rat receptor tyrosine-protein kinase: ErbB-2 ELISA kit was brought from Glory Science Co., Ltd (USA).

(d) ELISA (enzyme-linked immunosorbent assay) for rat estrogen detection: Estrogen ELISA kit was purchased from Glory Science Co., Ltd (USA).

(e) Colorimetric approach for evaluating the total antioxidant capacity which obtained from the Biodiagnostic Company (Egypt).

(f) Colorimetric method for lipid peroxide (malonaldehyde) determination which was purchased from the Biodiagnostic Company (Egypt).

\section{Histopathological evaluation of the mammary glands}

This was performed according to the methods of Bancroft and Stevens (1996). In the buffered formalin solution, the breast was removed and fixed. Then, in flowing tap water, the tissue was washed and dehydrated in an ascending alcohol sequence (50-90) and then in absolute alcohol. The tissue was cleared with xylol and immersed in an oven at $60{ }^{\circ} \mathrm{C}$ in a mixture of xylol and paraffin. The tissue was transported to pure paraffin wax $\left(58{ }^{\circ} \mathrm{C}\right.$ melting point) and then mounted on blocks until the time of use left at $4{ }^{\circ} \mathrm{C}$. The paraffin blocks were sectioned at a thickness of 4-6 $\mu \mathrm{m}$ on the microtome and mounted on clean glass slides, then left to dry at $40{ }^{\circ} \mathrm{C}$ in the oven. The slides were deparaffinized in xylol and then submerged in the downward alcohol sequence (90-50). For histological examination, the ordinary hematoxylin and eosin stain (H\&E stain or HE stain) were used.

\section{Statistical analysis}

The statistical analysis was done through using Snedecor and Cochron (1989) method. Within the given groups, all parameters were assessed through statistical software packages, namely (SPSS Software, version 16.0 for Windows; SPSS Inc., Chicago, IL). For the evaluation of the statistical significance of discrepancies between sample mean values of quantitative data, the Student's $t$ test is the most suitable.

\section{Results}

Histopathological evaluation of the mammary glands

1- Control (injected animals): (Fig. 1): Mammary gland of rat showing adenocarcinoma. Notice proliferating anaplastic cells arranged in acini without basement membrane $(\mathrm{H} \& \mathrm{E} \times 400)$.

2- Normal Control: (Fig. 2): Rat mammary gland with normal acini and with cuboidal cell lining $(H \& E \times 400)$.

\section{Discussion}

Human breast cancer is one of the most well-known malignancies, representing almost 1 out of every 3 female tumors examined, and it is the second leading cause of cancer death among women (DeSantis et al. 2011). In rats, 7,12-dimethylbenz[a]anthracene (DMBA) can inflict experimental breast carcinoma (Henry and Narendra 2006; Giri et al. 1995). Several tissues are appropriate for DMBA initiating and the mammary gland is integrated into them. DMBA is altered in the breast through epoxides, the active metabolites with the power to damage the DNA molecule, the headliner at the beginning of carcinogenesis. With the higher cell proliferative list of types 1 and 2 lobules, there are more metabolic capacity and more epoxide generation. Mammary carcinomas in rats are professed to emerge in the little mammary ducts (Russo et al. 1977; Sinha and Dao 1975; Middleton 1965) or from hyperplastic alveolar nodules (Beuving and Bern 1972; Beuving 1966).

Nanomedicine has many benefits compared to conventional cancer therapies, such as less drug degradation during transport via protection from in vivo chemical or biological conditions, minimized adverse effects via enhanced biocompatibility and targeting, and increased dosage of chemotherapy administered to the cancer tissue. Nanomedicine also possesses tremendous potential 


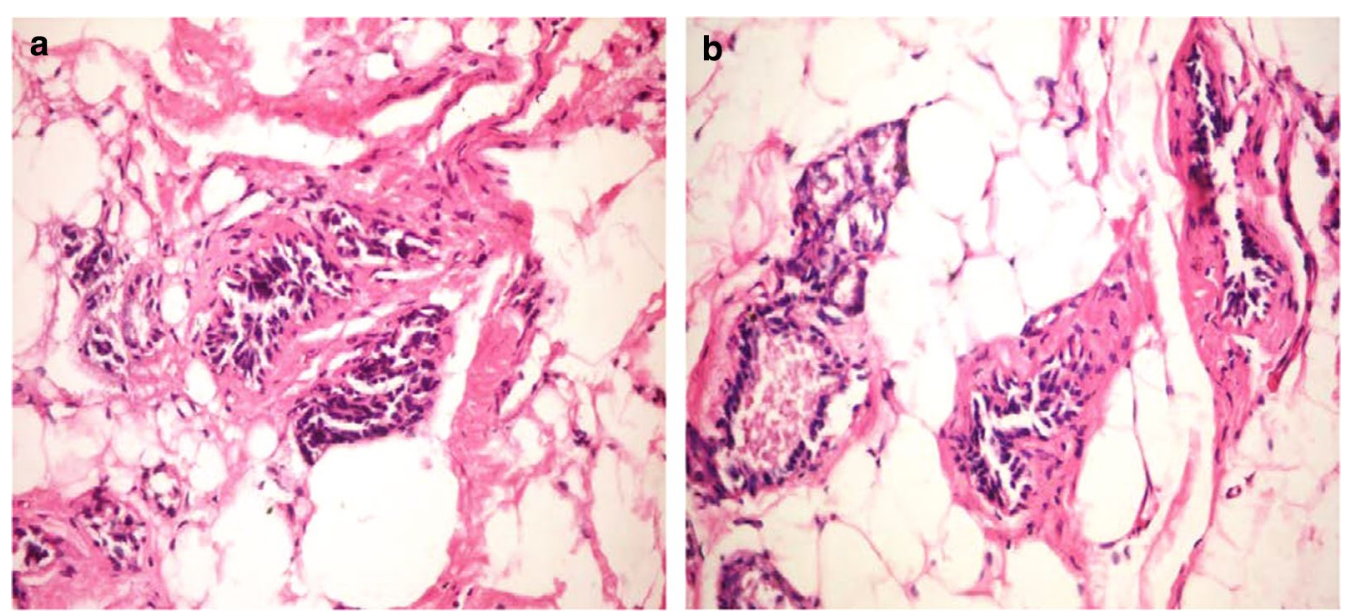

Fig. 1 a, b Rat mammary gland with adenocarcinoma. Notice proliferating anaplastic cells arranged in acini without basement membrane $(\mathrm{H} \& \mathrm{E} \times 400)$. [Control (injected animals)]

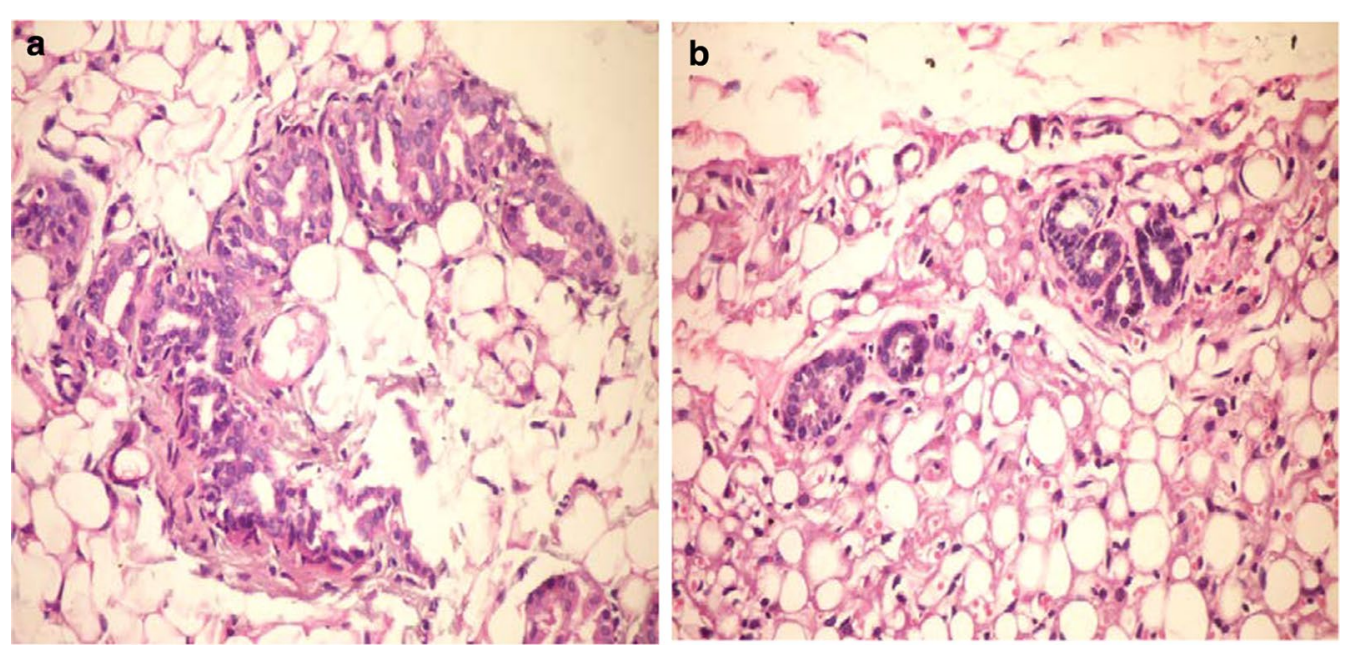

Fig. 2 a, b Mammary gland of rat showing normal acini with cuboidal cell lining (H\&E $\times 400)$. [Normal Control]

to selectively target and kill stem cells of breast cancer, which is a major factor in the initiation, recurrence and resistance to chemo-/radiotherapy of breast cancer.

The findings obtained exhibited the presence of anatomical damage to breast animals due to the DMBA infusion, causing breast cancer. As of now, a breast tumor by microscopic analysis of breast cells infected rats in contrast to normal animals was also orchestrated from the after effects of the current study by means of infusion DMBA (Figs. 1, 2). The results were consistent with numerous previous reports which detailed that numerous mammary gland dysplasia and mammary carcinomas emerge at whatever point 7,12-dimethylbenz[a] anthracene (DMBA) is given to the rat (Beuving et al. 1976, 1967; Van Duuren and Rubin 1971; Huggins and
Brillantes 1961). In some rat mammary glands, transformations are triggered by means of cancer-causing agents. Thus, as revealed in various studies, we will address the connection between nanotechnology in drugs as tamoxifen and certain bioactive compounds (yeast, isoflavone, and silymarin) associated with rat breast cancer.

Table 2 demonstrates that the apoptosis level, which is known to be a natural defense of the body to restrict the progression of a cancerous tumor, was correlated with an elevation in the lipid peroxidation level in all nanoprevention groups, including yeast, tamoxifen, and isoflavones, as opposed to the same normal prevention groups. The significance of apoptosis in tissue homeostasis is examined by the undeniable reality that many tumor genes like p53 and ERb tumor suppressor 
Table 2 Compared the influence of nano- and normal bioactive compounds on apoptosis, 8-OHdG, ErbB-2, plasma estrogen, lipid peroxide and total antioxidant (prevention experiment)

\begin{tabular}{|c|c|c|c|c|c|c|}
\hline Group & $\begin{array}{l}\text { Rat apoptosis } \\
\text { inducing factor } \\
\mathrm{Pg} / \mathrm{ml}\end{array}$ & $\begin{array}{l}\text { 8-OHdG } \\
\mathrm{ng} / \mathrm{L}\end{array}$ & $\begin{array}{l}\text { ErbB-2 } \\
\mathrm{pg} / \mathrm{ml}\end{array}$ & $\begin{array}{l}\text { Plasma estrogen } \\
\mathrm{pg} / \mathrm{ml}\end{array}$ & $\begin{array}{l}\text { Lipid peroxide } \\
\mathrm{nmol} / \mathrm{ml}\end{array}$ & $\begin{array}{l}\text { Total } \\
\text { antioxidant } \\
\mathrm{mM} / \mathrm{L}\end{array}$ \\
\hline \multicolumn{7}{|l|}{ Nanoyeast(I) } \\
\hline Mean $\pm S E^{* *}$ & $33.67 \pm 5.98$ & $6.67 \pm 0.025$ & $764.5 \pm 36.02$ & $106.37 \pm 3.92$ & $28.18 \pm 1.22$ & $0.775 \pm 0.019$ \\
\hline \multicolumn{7}{|c|}{ Normalyeast $(V)$} \\
\hline Mean $\pm S E^{* *}$ & $19 \pm 3.3$ & $5.7 \pm 0.14$ & $578.7 \pm 20.6$ & $126.5 \pm 1.73$ & $8.9 \pm 0.22$ & $0.85 \pm 0.014$ \\
\hline$P$-value & $P<0.05$ & $P<0.0005$ & $P<0.005$ & $P<0.0005$ & $P<0.0005$ & $P<0.005$ \\
\hline \multicolumn{7}{|c|}{ Nanotamoxifen (II) } \\
\hline Mean $\pm S E^{* *}$ & $44.3 \pm 8.04$ & $1.76 \pm 0.143$ & $1013 \pm 63.6$ & $100.5 \pm 5.99$ & $28.1 \pm 0.45$ & $0.72 \pm 0.052$ \\
\hline \multicolumn{7}{|c|}{ Normal tamoxifen (VI) } \\
\hline Mean \pm SE & $26 \pm 2.8$ & $6 \pm 0.15$ & $1593 \pm 130.8$ & $123 \pm 1.89$ & $11.4 \pm 0.59$ & $0.77 \pm 0.02$ \\
\hline$P$-value & $P<0.05$ & $P<0.0005$ & $P<0.005$ & $P<0.005$ & $P<0.0005$ & N.S \\
\hline \multicolumn{7}{|c|}{ Nanoisoflavone (III) } \\
\hline Mean $\pm S E^{* *}$ & $89.4 \pm 20.5$ & $6.5 \pm 0.03$ & $589.3 \pm 22.86$ & $95.2 \pm 4.07$ & $27.1 \pm 2.37$ & $0.75 \pm 0.011$ \\
\hline \multicolumn{7}{|c|}{ Normal isoflavone (VII) } \\
\hline Mean $\pm \mathrm{SE}^{* *}$ & $25.2 \pm 3.11$ & $6.7 \pm 0.02$ & $626 \pm 16.15$ & $126.7 \pm 3.76$ & $17.4 \pm 0.48$ & $0.73 \pm 0.011$ \\
\hline$P$-value & $P<0.01$ & $P<0.0005$ & N.S & $P<0.0005$ & $P<0.005$ & N.S \\
\hline \multicolumn{7}{|c|}{ Nanosilymarin (IV) } \\
\hline Mean $\pm S E^{* *}$ & $22.1 \pm 6.13$ & $4.8 \pm 0.27$ & $586.5 \pm 21.6$ & $101.8 \pm 6.67$ & $15.7 \pm 1.16$ & $0.78 \pm 0.02$ \\
\hline \multicolumn{7}{|c|}{ Normal silymarin (VIII) } \\
\hline Mean $\pm S E^{* *}$ & $20.8 \pm 1.17$ & $6.1 \pm 0.03$ & $849.5 \pm 63.8$ & $136.8 \pm 1.25$ & $14.8 \pm 1.28$ & $0.84 \pm 0.014$ \\
\hline$P$-value & N.S & $P<0.0005$ & $P<0.005$ & $P<0.0005$ & N.S & $P<0.025$ \\
\hline
\end{tabular}

**A significant elevation in apoptosis and lipid peroxide levels were observed in the nanoprevention groups (group 1 (yeast), group 2 (tamoxifen), and group 4 (isoflavone)) as opposed to the same normal prevention groups. The findings demonstrated a substantial reduction in the level of 8-OHdG in group 2 (nanotamoxifen), group 4 (nanoisoflavone), and group 3 (nanosilymarin) compared with the same normal prevention groups. On the contrary, the substantial of plasma 8-OHdG was matched in group 1 (nanoyeast) in comparison with the same normal group. The findings demonstrated a substantial reduction in estrogen levels in all nanoprevention groups in comparison with the same normal groups. The ErbB-2 level displayed a large elevation in group 1 (nanoyeast) in comparison with group 5 (normal yeast). The findings demonstrated a substantial decrease in the ErbB-2 level in each of group 2 (nanotamoxifen) in comparison with group 6 (normal tamoxifen), and group 4 (nanoisoflavone) when as compared group 8 (normal isoflavone). Total antioxidant findings demonstrated a large reduction for each of group 1 (nanoyeast) relative to group 5 (normal yeast) and group 4 (nanoisoflavone) in comparison with group 8 (normal isoflavone)

genes are affected and can be incited by several factors, like beams, medications, and contaminants (Yang and Korsmeyer 1996). The Bcl-2 family is important genes affecting apoptosis. Apoptosis can either strengthen or suppress the proteins encoded by these genes (Kimmo et al. 1999). Current research, including the apoptosis function, focuses on a broader understanding of the response and degree of resistance to amelioration. Data were summarized and integrated on apoptosis and its own role in the progression, anticipation, and amelioration of rat breast cancer. The natural progression of the breast was accounted for by a balance between cell multiplication and apoptosis and there is clear evidence that uncontrolled proliferation is not the only cause of tumor progression yet in addition as a result of lessened apoptosis. In view of different improvements, the balance among multiplication and apoptosis is invaluable in distinguishing the whole progression or relapse of the tumors. It is therefore conceivable, by assessing apoptosis and its own regulation and standards, to delineate the biology of specific tumors at the molecular and biochemical stage (Parton 2001).

The results obtained revealed that rat apoptosis inducing factor was highly elevated in all the investigated nanoformulations with regard to nanoisoflavone that showed the most promising results.

The findings demonstrated a substantial reduction in the amount of estrogen level in all groups of bioactive nanoprevention groups, superior in their natural form to the same bioactive groups. Numerous authors indicated that estrogen is a hormone participating in essential roles amid mammary gland progression, yet essential as a progression risk of breast cancer (Katchy and Williams 2014). Apart from the nan yeast community, which reported a high level of 8-OHdG in conjunction with the same normal yeast group, the findings of $8-\mathrm{OHdG}$ showed a substantial reduction in all nanoprevention groups. 8-OHdG is an oxidized nucleoside excreted by DNA repair in body fluids (Chapple and Matthews 2007; Chapple 1997). Serum 8-OHdG level has been shown to be very sensitive 
and precise marker in the medical diagnosis of rat breast cancer, and serum $8-\mathrm{OHdG}$ levels can be utilized as a noninvasive strategy for the screening process for rat breast cancer. A substantial raise in the ErbB-2 level was also shown. The reduction in the amount of total antioxidants may be due to the only elevation corresponding in the level of 8-OHdG in the nanoyeast group, as it is clear that in all nanoprevention groups, the findings revealed a reduction aside from the nanoyeast group, as opposed to the same normal prevention. Native change: both nanotamoxifen and silymarin were matched with a reduction in the ErbB-2 level. ErbB-2 (HER-2) had been accounted for being commonly over-expressed in breast cancer and is approached with the drug trastuzumab (Herceptin). As the level-resistance mechanism hasn't yet been elucidated, only one-third of women respond to trastuzumab. The preponderance of proof demonstrates that amplification of the HER-2/neu gene and overexpressions of proteins are associated with a detrimental outcome in human breast cancer. In addition, the silymarin group additionally demonstrated a slight massive reduction in the total antioxidant level, regardless of the fact that the 8-OHdG level was decreased, interestingly, the yeast group demonstrated a high 8-OHdG level with a reduction in the total antioxidants level. The elevated level of lipid peroxide in that group (yeast) that didn't have any noticeable shift in the nanosilymarin group could be due to it. Additionally, it is conceivable that the elevate in the level of ErbB-2 in the nanoyeast group is attributable to the elevation in the level of $8-\mathrm{OHdG}$ and the lessened level of antioxidants in the nanoyeast group relative to the same normal yeast group. In a previous study, yeast was found to be a promising an anticancer agent that incites significant in vivo levels of apoptosis in malignant cells. Be that as it may, yeast therapy for the breast cancer amelioration can currently not appear to be supervised in restorative clinical trials (Ghoneum et al. 2007).

The consequences of biochemical changes associated with rat breast cancer on the prevention of experimental animals have been demonstrated by the results of comparability among nano- and normal bioactive components forms. Where indeed, in comparison with normal tamoxifen, which achieved the highest positive results as indicated by signs and biochemical results or biochemical proof of the level of resistance to rat breast cancer, the nanotamoxifen group showed the best positive results in the level of resistance to rat breast cancer and furthermore as opposed to the consequences of biochemical indications of the other nanoparticle (silymarin-yeastisoflavones). High estrogen levels are a major risk factor for developing hormone-dependent diseases, including cancer of the breast. Tamoxifen, as an anti-estrogen, is perceived to be the first-line endocrine therapy for the prevention and amelioration of human breast cancer (Christinat et al. 2013). The side influence of tamoxifen has been perceived via recent studies. Numerous clinical studies have focused on discovering complementary substances that can synergize and diminish the side influences of tamoxifen (Yaacob et al. 2014; Dias et al. 2013). The beneficial relationship among tamoxifen and certain nutrients have been determined to reduce the medicinal side influences of tamoxifen amelioration or prevention (Tham et al. 1998). Perhaps it is said that the utilization of tamoxifen in the form of nanoparticles demonstrates positive influences, the main of which, in comparison with the natural form of tamoxifen, raise the incident and actuation of apoptosis mechanism besides minimizing the signs or symptoms of rat breast cancer ErbB-2 and 8-OHdG and minimizing the estrogen level and demonstrated the consequences of high lipid peroxidation level. It's conceivable that transformation of tamoxifen into the form of nanoparticles that allows the molecules to be separated has instigated the generation of free radicals that have just incited and raise the level of apoptosis. In antioxidant sources like isoflavones and silymarin, this might not have been demonstrated. The results were consistent with researches that demonstrated the power of free radicals and their relationship with antioxidants to elevate the progression of apoptosis in light of the programmed death of the diseased cells. Where the cellular fate has been accounted for, it is manipulated both endogenously and exogenously via means of various factors inside the cell, including a plenitude of gene level and defences against free radicals. Free radical species are in charge of regulating numerous processes of progression, differentiation, and death including apoptosis. Besides, numerous antioxidants and antioxidant enzymes tend to be equipped for anticipating apoptosis prompted via a variety of agents (Mates 2000).

The results of other positive biochemical indicators demonstrate signs of diminishing the progression of rat breast cancer via nanotamoxifen. The second best biochemical influence and biochemical indicator for the improvement of rat breast cancer is the nanoisoflavone prevention group. Despite the fact that the nanosilymarin group didn't indicate activation of the mechanism of programmed cell death, it demonstrated positive indications of 8-OHdG, ErbB-2, and estrogen levels being reduced. The mechanism of silymarin as an antioxidant could not be reactivated by apoptosis. As of now, the amount of lipid peroxidation was not matched a major change substantially and the level of total antioxidants that may have been devoured in an attempt to create a balance between lipid peroxidation and antioxidants had diminished. In view of its antioxidant power and 
free radical scavenging, silymarin has been stated to have cytoprotection activities. Silymarin has been demonstrated to have the growth inhibitory consequence of cell proliferation suppression and the incidence of apoptosis (Ramakrishnan et al. 2009). Likewise, polyphenol research which incorporates silymarin was viewed as a promising field in the amelioration and prevention of human breast cancer was also accounted for.

To block and postpone the microscopic stages of carcinogenesis, three fundamental methodologies were discovered (Mocanu et al. 2015; De Flora and Ferguson 2005; Flora et al. 2001). A preventive approach which obstructs toxic and mutagenic influences is a key technique, which consequently anticipates tumor initiation and promotion. Amid the early stages of carcinogenesis, the secondary strategy poses anti-cancer potential by various mechanisms, including the supermacy of signal transduction, angiogenesis prevention, antioxidant mechanisms, hormones, and immune modulation, which at last causing cancer progression to be blocked. By controlling cell adhesion molecules, shielding the extracellular matrix (ECM) from degradation, and upregulation genes that block metastasis, the third cancer amelioration and prevention strategy involves obstructing the invasiveness and metastatic functions of a tumor (De Flora and Ferguson 2005; Flora et al. 2001).

\section{Conclusion}

- Based on our data, we hypothesize that the utilization of tamoxifen in the form of nanoparticles has investigated positive influences, the most essential of which raise the occurrence and activation of mechanism of apoptosis besides minimizing the signs of ErbB-2 and 8-OHdG breast cancer and minimizing the amount of estrogen relative to the natural form of tamoxifen and demonstrated the results of high lipid peroxidation levels. Transforming tamoxifen and some bioactive compounds into a type of nanoparticles that induces molecular spacing could have induced the generation of free radicals that have already helped to induce and elevate the apoptosis level.

- One of the domains of modern needs of several considerable types of researchers and researches is nanotechnology in micronutrients and their relationship to health or disease. Nanotechnology is one of the essential domains that may be used to ameliorate certain disease on a massive scale and mitigate their progression.
Abbreviations

8-OHdG: Rat 8-Hydroxy deoxyguanosine; $\mathrm{BCl}-2$ : Human breast cancer genes 1 and 2; DMBA: 7,12-Dimethylbenz[a]anthracene; ErbB-2: Rat receptor tyrosineprotein kinase; MDA: Lipid peroxide (malonaldehyde); Res: Estrogen receptors; ROS: Reactive oxygen species; TAM: Tamoxifen; TEM: Transmission electron microscope.

\section{Acknowledgement}

I'd like to express my gratitude to all of the study's authors, as well as the National Research Centre.

\section{Authors' contributions}

AE conceived of the research work, devised the work plan, performed supervision, wrote and reviewed the manuscript; AA was in charge of the manuscript's supervision and analysis; MA was involved in identifying the issue, providing supervision, and assisting with the writing of the manuscript; $\mathrm{RD}$ was assisted in the writing of the manuscript and was present during the experiment in the open field; DM was the one who prepared the samples, conducted the experiment in the open area, assisted with data analysis and visualization, and submitted it to the BNRC. The final manuscript was revised, read, and accepted by all authors.

\section{Funding}

All sources of funding were from National Research Centre.

\section{Availability of data and materials}

The materials, the generated and analyzed data during this study are included in this published article.

\section{Declarations}

\section{Ethics approval and consent to participate}

The animal experiment was conducted in compliance with the U.K. Animals (Scientific Procedures) Act, 1986 and related guidelines; the Medical Research Ethics Committee (MREC) had reviewed and approved EU Directive 2010/63/ EU on animal experiments and the use of animals. It was carried out for studies involving animals with the registration number 14040, in compliance with the World Medical Association code of ethics. It was accompanied by national regulations on the treatment and use of laboratory animals.

\section{Consent for publication}

Not applicable.

\section{Competing interests}

All authors declare that they have no competing interests.

\section{Author details}

${ }^{1}$ Department of Nutrition and Food Science, National Research Centre, Dokki, Cairo 12622, Egypt. ${ }^{2}$ Faculty of Science, Cairo University, Giza, Egypt. ${ }^{3}$ Microbial Biotechnology Department, National Research Centre, Dokki, Cairo 12622, Egypt.

Received: 5 March 2021 Accepted: 12 April 2021

Published online: 21 April 2021

\section{References}

Angeline Kirubha SP, Anburajan M, Venkataraman B, Akila R, Sharath D, Raj B (2012) Evaluation of mammary cancer in 7,12-dimethylbenz(a) anthracene-Induced wister rats via asymmetrical temperature distribution analysis using thermography: a comparison with serum CEALevels and histopathology. J Biomed Biotechnol 786417:11

Bancroft D, Stevens A (1996) Theory \& practice of histological techniques, 4th edn. Churchill Livingstone, Edinburgh (ISBN 10: 044304760X/ISBN 13: 9780443047602)

Bertrand N, Wub J, Xiaoyang Xu, Kamaly N, Farokhzad OC (2014) Cancer nanotechnology: the impact of passive and active targeting in the era of modern cancer biology. Adv Drug Deliv Rev 66:2-25 
Beuving $\sqcup$ (1966) Influences of ovariectomy on preneoplastic nodule formation and maintenance in the mammary glands of carcinogen-ameriolateed rats. J Natl Cancer Inst 43(5):1181-1189

Beuving $\sqcup$, Bern HA (1972) Hormonal influence upon normal, preneoplastic, and neoplastic mammary gland. In: Dao TL (ed) Estrogen target tissues and neoplasia. University of Chicago Press, Chicago, IL, pp 257-273

Beuving $\sqcup$, Bern HA, DeOme KB (1976) Occurrence and transplantation of carcinogen-induced hyperplastic nodules in Fisher rats. J Natl Cancer Inst 39:431-447

Beuving $\sqcup$, Faulkin LJ, DeOme KB, Bergs WV (1967) Hyperplastic lesions in the mammary glands of Sprague-Dawley rats after 7,12-dimethylbenz[a] anthracene ameriolatement. J Natl Cancer Inst 39:423-429

Briggs GM, William MA (1963) A new mineral mixture for experimental rat diets \& evaluation of other mineral mixture. Fed Proc 122:261-266

Brody JG, Rudel RA, Michels KB, Moysich KB, Bernstein L et al (2007) Environmental pollutants, diet, physical power, body size, and breast cancer: where do we stand in research to identify opportunities for prevention? Cancer 109:2627-2634

Chapple IL (1997) Reactive oxygen species and antioxidants in inflammatory diseases. J Clin Periodontol 24:287-296

Chapple IL, Matthews JB (2007) The role of reactive oxygen and antioxidant species in periodontal tissue destruction. Periodontol 43:160-232

Christinat A, Di Lascio S, Pagani O (2013) Hormonal therapies in young breast cancer patients: when, what and for how long? J Thorac Dis 5:S36-46

De Flora S, Ferguson LR (2005) Overview of mechanisms of cancer chemopreventive agents. Mutat Res Fundam Mol Mech Mutagen 591:8-15

DeSantis C, Siegel R, Bandi P, Jemal A (2011) Breast cancer statistics. CA Cancer J Clin 61(6):409-418

Dias MC, Furtado KS, Rodrigues MAM, Barbisan LF (2013) Influences of Ginkgo biloba on chemically-induced mammary tumors in rats receiving tamoxifen. BMC Complement Changenative Med 13:93

Ezzat A, Abdelhamid AO, Amin Al, Abdelazeem AS, Mohammded DM (2013) Biochemical studies on the effect of nano particles of some nutrients on apoptosis modulation of breast cancer cells in experimental animals. J Appl Sci Res 9(1):658-665

Ezzat A, Abdelhamid AO, El Awady MK, Abd El Azeem AS, Mohammed DM (2017) The biochemical effects of nano tamoxifen and some bioactive components in experimental breast cancer. Biomed Pharmacother 95:571-576

Ezzat A, Abdelhamid AO, Mohammed DM (2018) The role of tamoxifen and some bioactive compounds in resistance to the development of toxicity causing breast cancer in experimental animals. SDRP J Food Sci Technol 3(5):440-449

Flora S, Izzotti A, D'Agostini F, Balansky RM, Noonan D, Albini A (2001) Multiple points of intervention in the prevention of cancer and other mutationrelated diseases. Mutat Res Fundam Mol Mech Mutagen 480:9-22

Ghoneum M, Wang L, Agrawal S, Gollapudi S (2007) Yeast therapy for the ameriolatement of breast cancer: a nude mice model study. Vivo 21(2):251-258

Giri U, Sharma SD, Abdulla M, Athar M (1995) Evidence that in situ gene level reactive oxygen species act as a potent stage I tumor enhancer in mouse skin. Biochem Biophys Res Commun 209:698-705

Girish CH, Vijayalakshmi P, Mentham R, Rao CB, Priyadarshini SN (2014) A review on breast cancer. Int J Pharm Bio Sci 4:47-54

Hayes J, Richardson A, Frampton C (2013) Population attributable risks for modifiable lifestyle factors and breast cancer in New Zealand women. IMJ 43(11):1198-1204

Henry L, Narendra PS (2006) Oral artemisinin prevents and delays the progression of 7,12-dimethylbenz[a]anthracene (DMBA)-induced breast cancer in the rat. Cancer Lett 231:43-44

Huggins CG, Brillantes LCFP (1961) Mammary cancer induced via a single feeding of polynuclear hydrocarbons, and its suppression. Nature 189:204-207
Katchy A, Williams C (2014) Profiling of Estrogen-regulated MicroRNAs in breast cancer cells. J Vis Exp 84:e51285

Kimmo MV, Raunio LH, Pääkkö P, Soini Y (1999) Apoptosis during breast carcinoma progression. Clin Cancer Res 5:319-324

Mates JM (2000) Influences of antioxidant enzymes in the molecular control of reactive oxygen species toxicology. Toxicology 153:83-104

Middleton PJ (1965) The histogenesis of mammary tumors induced in the rat via chemical carcinogens. Br J Cancer 19(4):830-839

Misra R, Acharya S, Sahoo SK (2010) Cancer nanotechnology: application of nanotechnology in cancer therapy. Drug Discov Today 15:19/20

Mocanu MM, Nagy P, Szöllosi J (2015) Chemoprevention of breast cancer via dietary polyphenols. Molecules 20:22578-22620

Morcos SR (1976) The influence of the protein value of the diet on the neurological manifestations produced in rats via $\beta$-immodipropionitrite. $\mathrm{Br} J$ Nutr 21:269-274

Parton M (2001) Researches of apoptosis in breast cancer. BMJ 322(7301):1528-1532

Ramakrishnan G, Lo Muzio L, Elinos-Baez CM, Jagan S, Augustine TA, Kamaraj S et al (2009) Silymarin inhibited proliferation and induced apoptosis in hepatic cancer cells. Cell Prolif 42:229-240

Russo J, Savia J, Isenberg WM, Russo IH (1977) Pathogenesis of mammary carcinomas induced in rats via 7, 12-dimethylbenz[a]anthracene. J Natl Cancer Inst 59:435-445

Samy RP, Gopalakrishnakone P, Ignacimuthu S (2006) Anti-tumor promoting the potential of luteolin against 7,12-dimethylbenz[a]anthraceneinduced mammary tumours in rats. Chem Biol Interact 164:1-14

Simpson PT, Reis-Filho JS, Lakhani SR (2010) Lobular carcinoma in situ. Biology and pathology. In: Harris JR, Lippman ME, Morrow M, Osborne CK (eds) Diseases of the breast, 4th edn. Lippincott Williams \& Wilkins, Philadelphia, PA, pp 333-340

Sinha D, Dao TL (1975) Site of origin of mammary tumors induced via 7,12-dimethylbenz[a]anthracene in the rat. J Natl Cancer Inst 54(4):1007-1009

Snedecor GW, Cochron WG (1989) Statistical methods, 8th edn. Lowa State University Press, Ames, Lowa (ISBN-10: 0813815614/ISBN-13: 978-0813815619)

Teunissen SF, Rosing H, Schinkel AH, Schellens JH, Beijnen JH (2010) Bioanalytical methods for determination of tamoxifen and its phase I metabolites: a review. Anal Chim Acta 683:21-37

Tham DM, Gardner CD, William L (1998) Haskell. Potential health benefits of dietary phytoestrogens: a review of the clinical, epidemiological, and mechanistic evidence. J Clin Endocrinol Metab 83(7):2223-2235

Van Duuren BL, Rubin BA (1971) Inhibition of carcinogenesis. Prog Tumor Res Basel Karger 14:59-88

Yaacob NS, Kamal NN, Norazmi MN (2014) Synergistic anticancer influences of a bioactive subfraction of Strobilanthes crispus and tamoxifen on MCF-7 and MDA-MB-231 human breast cancer cell lines. BMC Complement Changenative Med 14:252

Yang E, Korsmeyer SK (1996) Molecular thanatopsis: a discourse on the BCl-2 family and cell death. Blood 88:386-401

Zhang Y, Lv F, Yang Y, Qian X, Lang R et al (2015) Clinicopathological features and prognosis of metaplastic breast carcinoma: experience of a main chinese cancer center. PLOS ONE 10:e0131409

\section{Publisher's Note}

Springer Nature remains neutral with regard to jurisdictional claims in published maps and institutional affiliations. 